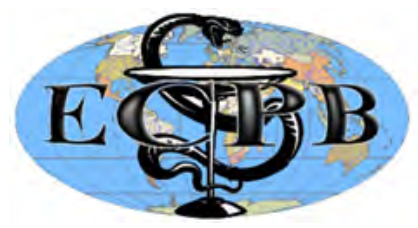

“ЕКСПЕРИМЕНТАЛЬНА ТА КЛІНІЧНА ФІЗІОЛОГІЯ І БІОХІМІЯ" "EXPERIMENTAL AND CLINICAL PHYSIOLOGY AND BIOCHEMISTRY" Науково-практичний журнал/Scientific-practical journal

Наукові статті / Research article

ECPB 2018, 1(81): 39-50. https://doi.org/

\title{
Relationships between changes in parameters of the manual function and electroencephalogram, heart rate variability as well as gas discharge visualization in children with spastic form of cerebral palsy caused by the Kozyavkin method
}

\author{
I.L. POPOVYCH ${ }^{1}$, V.Y. BABELYUK ${ }^{2}$, H.I. DUBKOVA ${ }^{2}$, T.A. KOROLYSHYN ${ }^{1,2}$, W. ZUKOW \\ 1 Bogomoletz Institute of Physiology of NAS, Kÿ̈v, Ukraine \\ 2 Clinical Sanatorium 'Moldova', Truskavets', Ukraine; \\ 3 Nicolaus Copernicus University, Torun', Poland \\ E-mail: i.popovych@biph.kiev.ua,w.zukow@.wp.pl
}

Introduction. It was reported earlier that after two-week course of Intensive Neurophysiological Rehabilitation System (INRS) officially recognized as the Kozyavkin method [18-20], the parameters of the functional tests of hands in 108 children with spastic forms of cerebral palsy (SFCP) have been significantly improved. The increase has been detected in Box and Block Test by 22,9 \pm $2,2 \%$ right and by $19,1 \pm 1,3 \%$ left, in Nine Hole Peg Test by $16,7 \pm 1,9 \%$ right and by 18,8 $\pm 1,8 \%$ left, in Dynamometry by 30,6 $\pm 5,0 \%$ right and by $31,6 \pm$ $6,1 \%$ left. In total the effectiveness of the restoration of functional parameters of hands by the Kozyavkin method makes on average $23,3 \pm 1,6 \%$ versus 3,5 $\pm 1,4 \%$ in control. However, the average indicators obscure the significant differences between individual children. In particular, in $58 \%$ of patients, changes are very tangible, in $22 \%$ - moderate, while in $20 \%$ are minor [21]. In another group of 29 children it was found out that reducing of the neural component of muscle tone (NCMT) was stated in $79,3 \%$ cases from $7,6 \pm 1,0 \mathrm{~N}$ to $1,6 \pm 0,5 \mathrm{~N}$ (direct difference: $-6,0 \pm 0,8 \mathrm{~N}$ ), while in $13,8 \%$ cases changes were not detected and in 2 children only NCMT increased from 1,6 to 3,4 and from 4,6 to $6,1 \mathrm{~N}$ respectively $[13,22]$.

It is known about abnormalities in the autonomous nervous system (ANS) in patients with CP $[1,14,29]$. Obviously, these abnormalities are associated with CNS damage. We have recently discovered the relationships between the parameters of heart rate variability (HRV) as markers of ANS activity and the background of EEG activity [31,32]. Proceeding from this we hypothesized that such a variety of changes in NCMT is due to ambiguous changes in the background activity of the nerve centers. For their evaluation the following HRV and Electroencephalography (EEG) methods (about Neuroimaging in the conditions of Ukraine we can only dream) are available. Since such children are not always able to register EEG and HRV due to uncontrolled movements, the search for other methods for evaluating neural activity remains relevant.

Back in 1880 Nikola Tesla demonstrated that when placing the man in the high-frequency field around the body there is a bright glow. In 1892 Y.O. Nardkevych-Yodko recorded a glow of human hands on a photographic plate. However, a well-known method of 'high-frequency photography' was due to the married couple S.D. and V.H. Kirlian who in 1939 independently

(C) Popovych I.L., Babelyuk V.Y., Dubkova H.I. та ін., 2018 
discovered this phenomenon, later called 'Kirlian's effect' [cit. by: 12]. In 1996 K.G. Korotkov created a new scientific approach based on the digital video technics, modern electronics and computer processing of quantitative data, called as the method of gas discharge visualization (GDV bioelectrography). The parallel use of the terms Kirlianography and Electrophotonics is observed. The method of GDV, essence of which consists in registration of photoelectronic emission of skin, induced by high-frequency electromagnetic impulses, allows to estimate the integrated psycho-somatic state of a body. The first base parameter of GDV is Area of Gas Discharge Image (GDI) in Right, Frontal and Left projections registered both with and without a polyethylene filter. The second base parameter is a coefficient of Shape (ratio of square of length of the external contour of GDI towards its area), which characterizes the measure of serration/ fractality of the external contour. The third base parameter of GDI is Entropy, it means the measure of chaos (disorder, uncertainty). It is considered that GDI, taken without any filter, characterizes the current psychophysiological condition of a body while registered with a filter characterizes the vegetative regulation at the level of stable physiological processes [16, 17]. Though the attitude to the method (between excellent and fickle) is ambiguous, previously the study on its verification was conducted which showed that GDV parameters are correlated with HRV [2-4] and EEG [5] parameters. In another study, we have shown that GDV parameters can change with changes in other functional parameters of the body [11,34].

The purpose of this study is to analyze the relationships between changes in NCMT as well as manual functional tests on the one hand, and parameters of EEG, HRV as well as GDV on the other hand, caused by the Kozyavkin method.

Material and Methods. The objects of the observation were 14 children (6 girls and 8 boys) aged $8 \div 15$ years with Spastic Forms of Cerebral Palsy. Diagnose, Stage, Phase as well as Gross Motor Function Classification System [33] and Manual Ability Classification System [8] levels are given in the Table 1.

Table 1

Clinical characteristics of the observed children

\begin{tabular}{|c|c|c|c|c|c|c|c|}
\hline Child & Gender & Age & Diagnose & Stage & Phase & GMFCS & MACS \\
\hline Hou L & Girl & 14 & $\begin{array}{c}\text { G80.0 CCP: spastic } \\
\text { tetraplegia }\end{array}$ & $\begin{array}{c}\text { movement } \\
\text { by turning }\end{array}$ & $\begin{array}{c}\text { lying to the } \\
\text { control head }\end{array}$ & 4 & 3 \\
\hline Myk & Boy & 10 & $\begin{array}{c}\text { G80.1 CCP: spastic } \\
\text { diplegia }\end{array}$ & $\begin{array}{c}\text { crawling on } \\
\text { their bellies }\end{array}$ & $\begin{array}{c}\text { independent } \\
\text { seat }\end{array}$ & 4 & 3 \\
\hline Pet & Girl & 10 & $\begin{array}{c}\text { G80.1 CCP: spastic } \\
\text { diplegia }\end{array}$ & $\begin{array}{c}\text { walking on } \\
\text { the knees }\end{array}$ & $\begin{array}{c}\text { getting up at } \\
\text { the support }\end{array}$ & 4 & 3 \\
\hline Hou D & Girl & 14 & $\begin{array}{c}\text { G80.1 CCP: spastic } \\
\text { diplegia }\end{array}$ & $\begin{array}{c}\text { walk with } \\
\text { aids }\end{array}$ & $\begin{array}{c}\text { independent } \\
\text { seat }\end{array}$ & 3 & 3 \\
\hline Pav & Boy & 9 & $\begin{array}{c}\text { G80.1 CCP: spastic } \\
\text { diplegia }\end{array}$ & $\begin{array}{c}\text { walk with } \\
\text { aids }\end{array}$ & riplegia \\
support near & aids & 3 & 2 \\
\hline Boj A & Boy & 15 & $\begin{array}{c}\text { G80.1 CCP: spastic } \\
\text { diplegia }\end{array}$ & $\begin{array}{c}\text { walk with } \\
\text { aids }\end{array}$ & self-rising & 2 & 2 \\
\hline Boj D & Boy & 15 & $\begin{array}{c}\text { G80.1 CCP: spastic } \\
\text { diplegia }\end{array}$ & $\begin{array}{c}\text { independent } \\
\text { moves }\end{array}$ & self-rising & 2 & 2 \\
\hline Vor & Boy & 9 & G80.1 CCP: spastic \\
diplegia & $\begin{array}{c}\text { independent } \\
\text { moves }\end{array}$ & self-ing & 2 & 2 \\
\hline
\end{tabular}




\begin{tabular}{|c|c|c|c|c|c|c|c|}
\hline Lan & Girl & 12 & $\begin{array}{c}\text { G80.2 CCP: spastic } \\
\text { hemiplegia Left }\end{array}$ & $\begin{array}{c}\text { independent } \\
\text { moves }\end{array}$ & $\begin{array}{c}\text { rising } \\
\text { support near }\end{array}$ & 2 & 2 \\
\hline Kul & Girl & 12 & $\begin{array}{c}\text { G80.1 CCP: spastic } \\
\text { diplegia }\end{array}$ & $\begin{array}{c}\text { altenative } \\
\text { crawling }\end{array}$ & $\begin{array}{c}\text { independent } \\
\text { seat }\end{array}$ & 4 & 3 \\
\hline Kuch & Girl & 13 & $\begin{array}{c}\text { G80.1 CCP: spastic } \\
\text { diplegia }\end{array}$ & $\begin{array}{c}\text { walk with } \\
\text { aids }\end{array}$ & $\begin{array}{c}\text { rising } \\
\text { support near }\end{array}$ & 3 & 3 \\
\hline Str & Boy & 12 & $\begin{array}{c}\text { G80.2 CCP: spastic } \\
\text { hemiplegia Left }\end{array}$ & $\begin{array}{c}\text { independent } \\
\text { moves }\end{array}$ & self-rising & 1 & 1 \\
\hline
\end{tabular}

The estimation of the hand function was carried out by Dynamometry, Box and Block Test and Nine Hole Peg Test. To measure the strength of the hand we used the dynamometer of 'Jamar' company [25]. In the study the patient is sitting on the chair or with a good fixation on the mother's knees. The hand performing measurements lowers to the torso, arms are along the body, elbows are bent at right angles, is on the anvil. The instructor explains and demonstrates the task in the correct way. 2-3 attempts are conducted to adapt and understand the task on each hand.

Box and Block Test is a simple, reliable and valid test of the hand function. This test was developed in 1985 by V.Mathiowetz [27] to assess the hand function in adults with cerebral palsy. It is widely used by specialists in the physical rehabilitation and ergotherapy. The essence of the test is to determine the number of wooden cubes that a patient can shift from one box to the second in a minute. A wooden box divided into two parts by a partition of $15 \mathrm{~cm}$ height is required for the test. One half of the box is 150 wooden blocks measuring 1 inch $(2,5 \mathrm{~cm})$. The patient is explained and shown how to rearrange blocks. At the command as soon as the patient begins to shift blocks from one box to the other half. The instructor places a patient and stops in one minute. First, the dominant hand is examined, then blocks are rearranged in the box and the second hand is inspected. The number of transmitted blocks is registered by each hand. The time allocated for the test is from three to five minutes.

The essence of Nine Hole Peg Test $[30,35]$ is to determine how long the patient can turn each hand and then remove wooden 9 pegs in 9 holes in the wooden bar. Before the test the ergotherapist shows the patient how to do it. At the command as soon as the patient begins to insert wooden plugs into the holes in the wooden bar. The instructor measured the time. The dominant hand is examined first, then the other one. [28]:

For each test the Laterality Index (LI) is calculated by using the equation

$$
\text { LI }=100 \% \cdot(\text { Right }- \text { Left }) / 0,5 \cdot(\text { Right }+ \text { Left })
$$

Neural, elastic and viscous components of the muscle tone were also registered by the device 'NeuroFlexor (Aggero MedTech AB, Sweden). The recent studies have indicated that the mentioned device is suitable for measurement of changes in spasticity during CP treatment [13, 9, 10, 23, 26].

The electrocardiogram was recorded in a sitting position during $7 \mathrm{~min}$ the next morning by means of the hardware-software complex 'CardioLab+HRV' ('KhAI-Medica', Kharkiv, Ukraine) to assess the parameters of HRV as markers of vagal and sympathetic outflows. For further analysis the following parameters HRV were selected as: a) temporal parameters (Time Domain Methods) - the standard deviation of all NN intervals (SDNN), the coefficient of variation (CV), the square root of the sum of the squares of differences between adjacent NN intervals (RMSSD), the percent of interval differences of successive NN intervals is greater than $50 \mathrm{~ms}\left(\mathrm{pNN}_{50}\right)$, the triangulary index (TINN); heart rate $(\mathrm{HR})$, moda (Mo), the amplitude of moda (AMo), variational sweep (MxDMn or $\Delta \mathrm{X})$; b) spectral parameters (Frequency Domain Methods) - spectral power (SP) bands of HRV: high-frequency ( $\mathrm{HF}$, range $0,4 \div 0,15 \mathrm{~Hz})$, low-frequency 


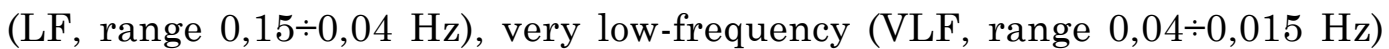
and ultra low-frequency (ULF, range $0,015 \div 0,003 \mathrm{~Hz}$ ). The relative $\mathrm{SP}$ of all bands as well as classical indexes $\mathrm{LF} / \mathrm{HF}$ and $\mathrm{LFnu}=100 \% \cdot \mathrm{LF} /(\mathrm{LF}+\mathrm{HF})[6,7$, 24] were calculated.

Simultaneously with HRV, EEG was recorded for 25 sec by using the hardware-software complex 'NeuroCom Standard' (KhAI Medica, Kharkiv, Ukraine) monopolar in 16 loci (Fp1, Fp2, F3, F4, F7, F8, C3, C4, T3, T4, P3, P4, T5, T6, O1, O2) by 10-20 international system, with the reference electrodes A and Ref tassels on the ears. Among the options the average EEG amplitude $(\mu \mathrm{V})$ was considered as well as the average frequency $(\mathrm{Hz})$, frequency deviation $(\mathrm{Hz})$, index (\%), coefficient of asymmetry (\%) as well as absolute $\left(\mu \mathrm{V}^{2} / \mathrm{Hz}\right)$ and relative (\%) spectral power density (SPD) in the standard frequency bands: $B$ $(35 \div 13 \mathrm{~Hz}), a(13 \div 8 \mathrm{~Hz}), \theta(8 \div 4 \mathrm{~Hz})$ and $\delta(4 \div 0,5 \mathrm{~Hz})$ in all loci, according to the instructions on the device.

In addition the Laterality Index (LI) was calculated for SPD of each Rhythm by using formula [28]:

$$
\text { LI, } \%=\Sigma[200 \cdot(\text { Right }- \text { Left }) /(\text { Right }+ \text { Left })] / 8
$$

The Kirlianogram has been registered by the method of GDV by means of the device 'GDV Chamber' (Biotechprogress', SPb, RF) [17].

After testing children received a classic course of rehabilitation during two weeks (a detailed description is provided in the manual [20]), then repeated the tests listed.

The digital material is treated by methods of factor analysis, cross-correlation and canonical analyses with the use of package of softwares 'Statistica-5.5' and the algorithm of Truskavets' scientific school of balneology [24,34].

Results and Discussion. It is stated that Neural Components of Muscle Tone (NCMT) were reduced in 9 children from $19,8 \pm 3,4$ to $12,3 \pm 2,8$ Newtons (change: $-7,5 \pm 2,0 \mathrm{~N} ; p<0,01$ ), in 3 children NCMT was $8,2 \pm 3,3$ before and $7,9 \pm 3,5$ after rehabilitation (change: $-0,3 \pm 0,3 \mathrm{~N}$ ) while in one girl NCMT was increased from 15,1 to $17,9 \mathrm{~N}$ as well as in one boy from 6,1 to $19,4 \mathrm{~N}$. Thus, the previously obtained data on the diversity of rehabilitation effects were confirmed.

According to the formula:

$$
|r| \geq\{\exp [2 t /(n-1,5) 0,5]-1\} /\{\exp [2 t /(n-1,5) 0,5]+1\}
$$

for a sample of 14 observations the critical value of correlation coefficient module $|\mathbf{r}|$ at $p<0,05(t>2,14)$ is $\mathbf{0 , 5 4}$, at $p<0,01(t>2,98)$ is $\mathbf{0 , 7 0}$, at $p<0,001(t>4,14)$ is $\mathbf{0 , 8 4}$. Nevertheless, in regressive models with step-bystep exclusion, there were separate variables with the values $|r|$ less than the critical level whereas some variables with meaningful modules were not included in the models.

The screening of pairwise correlations given in Table 2 showed that the favourable changes in manual tests (the increased number of transferred blocks and the strength of the hand, in connection with the reduction of the time of the 9-Hole Peg test and the decrease of the neural component of the muscle tone) are accompanied by the increase in the quantities of HRV-markers of the vagal tone together with the decrease in the sympathetic tone markers as well as probably on level of circulating the cathecholamines marker of ULF and VLF bands of HRV [15, 32] is possible.

As we can see from the modulus of the correlation coefficients, the most informative is the normalized HRV parameters that reflect the Vagal (HF/TP) and Sympathetic (LFnu) tones.

Judging from the estimation of the modulus of the correlation coefficients, changes in the tests of the Right hand are usually more sensitive to changes in the vago-sympathetic balance than of the Left one.

Regarding the EEG parameters, it seems that the increase of 5 of them is caused by adverse changes in manual tests, while favorable changes are caused 
by the increase in the other 5 EEG parameters regardless of frequency bands as well as the locus side.

Regarding the GDV parameters, it seems that the favorable changes in the manual functions are caused by the decrease, first of all, in the Entropy of the Gas-discharge Image (GDI) in the Right projection recorded by means of the filter (f) as well as its Symmetry and Area in Frontal projection, on the one hand, instead of the increase in Entropy in the same projection without any filter as well as in Frontal and Left projections with the filter and in Shape Coefficients of GDI, on other hand.

Table 2

Correlation matrix for changes in parameters of Manual Function and HRV, EEG, GDV

\begin{tabular}{|c|c|c|c|c|c|c|c|c|}
\hline Variables & B\&B R & B\&B L & D R & D L & 9-HP R & 9-HP L & NC MTL & Mean $|r|$ \\
\hline $\mathrm{HF} / \mathrm{TP}$ & ,86 &, 57 &, 61 &, 54 &,- 68 &,- 60 &,- 31 & 0,596 \\
\hline $\mathrm{HF}$ &, 52 & ,27 &, 54 &, 28 &,- 16 &,- 28 &, 07 & 0,303 \\
\hline LFnu &,- 78 &,- 63 &,- 45 &,- 45 &, 62 &, 53 & ,25 & 0,530 \\
\hline VLF &,- 48 &,- 35 &,- 25 &,- 40 & ,68 & , 43 &, 60 & 0,456 \\
\hline $\mathrm{ULF}$ &,- 43 &,- 31 &,- 64 &,- 49 &, 26 & ,64 &,- 11 & 0,411 \\
\hline $\mathrm{LF}$ &,- 38 &,- 44 &,- 02 &,- 26 &, 67 & ,31 &, 54 & 0,374 \\
\hline $\mathrm{ULF} / \mathrm{TP}$ &,- 31 &,- 30 &,- 60 &,- 55 &, 18 &, 47 &,- 10 & 0,359 \\
\hline Index $\theta$ &,- 52 &,- 53 &,- 73 &,- 75 & ,48 & ,63 &, 43 & 0,581 \\
\hline Deviation $\theta$ &,- 59 &,- 66 &,- 35 &,- 46 &, 50 & ,61 & ,25 & 0,489 \\
\hline Frequency a &,- 42 &,- 34 &,- 42 &,- 28 & 40 &, 58 & ,19 & 0,376 \\
\hline T3-8 SPDR &, 50 &,- 40 &,- 34 &,- 33 & 42 &, 50 & ,06 & 0,364 \\
\hline C3-a SPDA & , 12 &,- 14 &,- 05 &,- 26 & ,03 &, 10 &, 55 & 0,179 \\
\hline T4-8 SPDA & ,39 &, 52 &, 18 &, 09 &,- 36 &,- 41 &,- 11 & 0,294 \\
\hline Laterality a & ,01 & ,08 &, 14 &, 48 &,- 34 &,- 06 &,- 76 & 0,267 \\
\hline Amplitude $\theta$ & ,63 & ,30 &, 02 &, 03 &,- 51 &,- 21 &,- 13 & 0,261 \\
\hline F8-a SPDA &, 55 & ,27 & ,02 &, 07 &,- 43 &,- 27 & ,03 & 0,234 \\
\hline F3- $\theta$ SPDA &, 55 &, 13 &, 13 &, 06 &,- 44 &,- 13 &,- 14 & 0,226 \\
\hline Entropy R f &,- 57 &,- 34 &, 58 &, 46 &,- 64 &,- 75 &, 58 & 0,560 \\
\hline Symmetry f &,- 31 &,- 43 &, 40 &, 28 &,- 24 &,- 41 &, 41 & 0,354 \\
\hline Area F &,- 42 &,- 48 &, 51 & ,33 &, 00 &,- 18 &, 41 & 0,333 \\
\hline Entropy F f &, 64 &, 49 &,- 60 &,- 52 &, 50 &, 37 &,- 29 & 0,487 \\
\hline Shape Coef R &, 52 &, 52 &,- 36 &,- 61 &, 52 &, 26 &,- 02 & 0,401 \\
\hline Entropy L f & ,35 &, 51 &,- 42 &,- 52 &, 20 &, 37 &,- 42 & 0,399 \\
\hline Entropy R &, 62 &, 60 &,- 37 &,- 52 &, 37 &, 12 &,- 08 & 0,383 \\
\hline
\end{tabular}

Now let's compare the factor structures of the nervous structures (sorry for the pun), the changes in their activity cause changes in the functional tests of the Right and Left hands. It was found out (Table 3 and Fig. 1) that the improvement of functions of the Right hand is due to the increased vagus tone and SPD of generating $\theta$-rhythm nervous structures that are projected to the Left Frontalis medialis locus in combination with the decrease in the index and frequency of variation $\theta$-rhythm as well as the decrease in the sympathetic tone and the activity of generating B-rhythm of nervous structures that are projected to the Left Temporalis Anterior locus and probably on the level of circulating Cathecholamines. 
Factor Structure for changes in parameters of HRV and EEG (right set) and Function of Right Hand (left set)

\begin{tabular}{|l|c|}
\hline Right set & $\mathrm{R}$ \\
\hline HF/TP &, 757 \\
\hline HF SP &, 562 \\
\hline F3- $\theta$ SPDA &, 280 \\
\hline Amplitude $\theta$ &, 221 \\
\hline Index $\theta$ &,- 747 \\
\hline LFnu &,- 609 \\
\hline Deviation $\theta$ &,- 473 \\
\hline T3-B SPDR &,- 433 \\
\hline VLF SP &,- 391 \\
\hline Left set & $\mathrm{R}$ \\
\hline Dynamometry R &, 957 \\
\hline Box\&Block R &, 785 \\
\hline 9-Hole Peg R &,- 607 \\
\hline
\end{tabular}

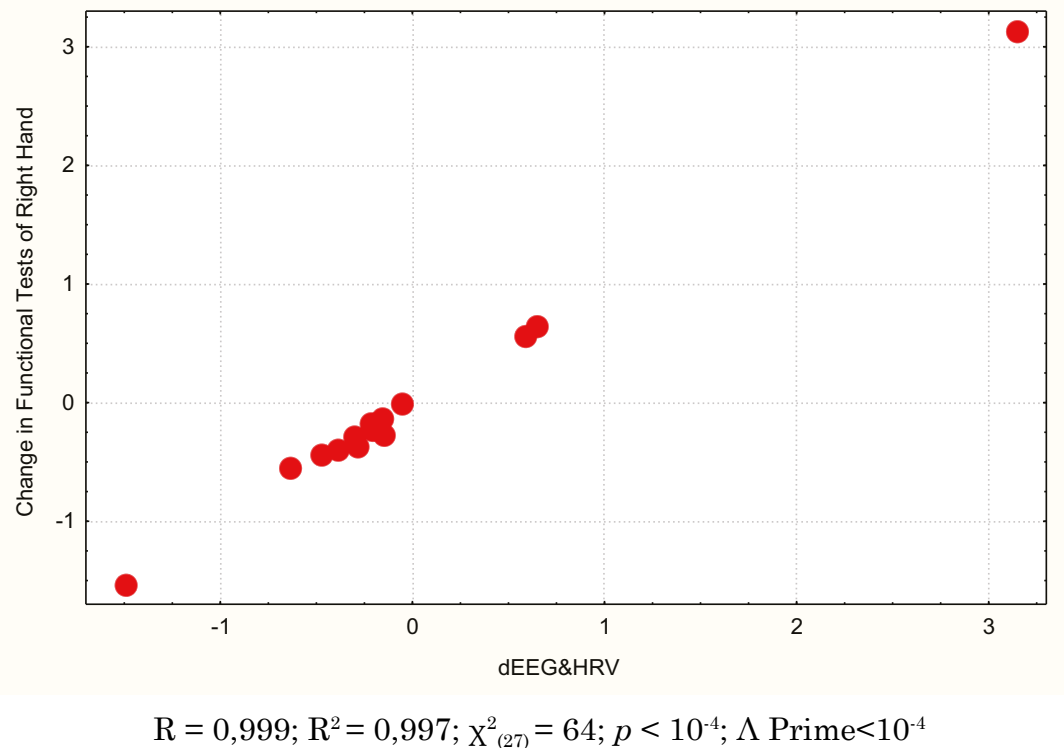

Fig. 1. Scatterplot of canonical correlation between changes in parameters of EEG\&HRV (line $\mathrm{X}$ ) and Function of Right hand (line Y)

Instead, in improving the functions of the Left hand, judging by the factor load, a greater role is played by the reduction of the level of catecholamines in blood, except for the decrease of the index and the deviation of $\theta$-rhythm as well as decrease in SPD generating B-rhythm of nervous structures that are projected to the Left and Right Temporalis Anterior loci (Table 4 and Fig. 2). It should be noted the beneficial effect of Right lateralization of a-rhythm.

The Right lateralization of a-rhythm is associated also with the decrease in NCMT of Left hand. This factor together with the weakening of sympathetic effects and the increase in the parasympathetic tone, determines the decline of the NCMT by $72 \%$ (Table 5 and Fig. 3). 
Table 4

Factor Structure for changes in parameters of HRV and EEG (right set) and Function of Left Hand (left set)

\begin{tabular}{|l|c|}
\hline Right set & $\mathrm{R}$ \\
\hline Index $\theta$ &, 642 \\
\hline ULF SP &, 546 \\
\hline VLF SP &, 319 \\
\hline T4-B SPDA &, 239 \\
\hline T3-B SPDR &, 213 \\
\hline Deviation $\theta$ &, 162 \\
\hline Laterality $\alpha$ &,- 525 \\
\hline Left set & $\mathrm{R}$ \\
\hline Dynamometry L &,- 834 \\
\hline 9-Hole Peg L &, 483 \\
\hline Box\&Block L &,- 166 \\
\hline
\end{tabular}

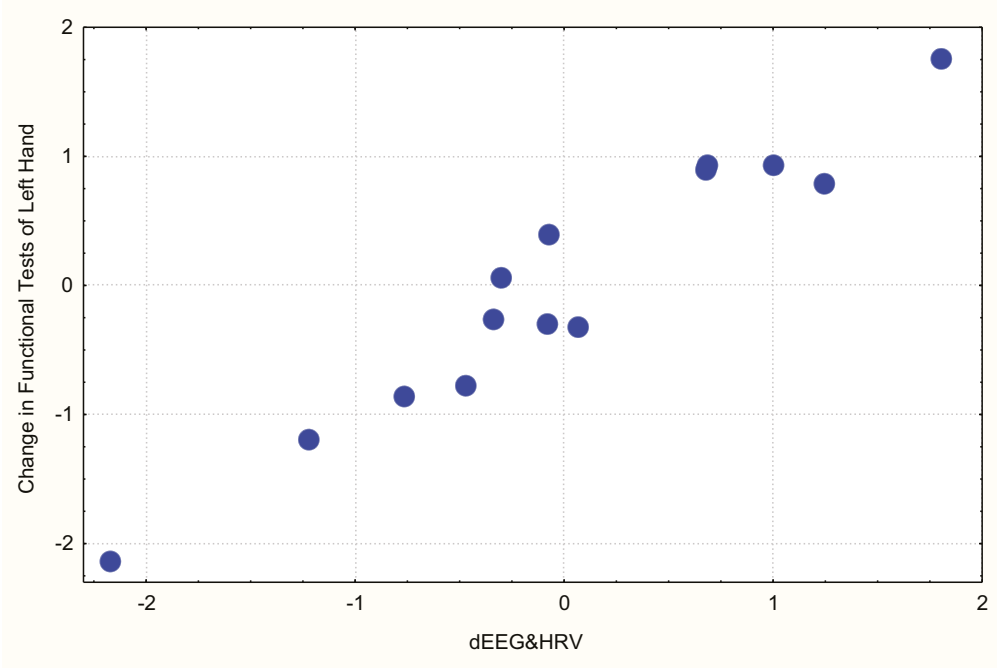

$\mathrm{R}=0,965 ; \mathrm{R}^{2}=0,931 ; \mathrm{X}_{(21)}^{2}=34 ; p=0,035 ; \Lambda$ Prime $=0,010$

Fig. 2. Scatterplot of canonical correlation between changes in parameters of EEG\&HRV (line $\mathrm{X})$ and Function of Left hand (line Y)

Table 5

\section{Regression Summary for changes in Dependent Variable: Neural Component of Muscle Tone}

$\mathrm{R}=0,887 ; \mathrm{R}^{2}=0,786$; Adjusted $\mathrm{R}^{2}=0,722 ; \mathrm{F}_{(3,1)}=12,2 ; p=0,001 ; \mathrm{SE}$ of estimate:4,1 Newtons

\begin{tabular}{|l|c|c|c|c|c|c|c|}
\hline $\begin{array}{c}\text { Change in } \\
\text { Independent } \\
\text { Variables }\end{array}$ & $\mathrm{r}$ & Beta & $\begin{array}{c}\text { St. Err. } \\
\text { of Beta }\end{array}$ & $\mathrm{B}$ & $\begin{array}{c}\text { St. Err. } \\
\text { of B }\end{array}$ & $\mathrm{t}_{(10)}$ & p-level \\
\cline { 3 - 8 } & & Intercpt & $-5,03$ & 1,23 & $-4,09$ &, 002 \\
\hline Laterality a, \% & $-0,76$ &,- 704 &, 160 &,- 2737 &, 0623 & $-4,39$ &, 001 \\
\hline HF/TP, \% & $-0,31$ &,- 286 &, 161 &,- 1650 &, 0931 & $-1,77$ &, 107 \\
\hline VLF SP, $\mathrm{ms}^{2}$ & 0,60 &, 268 &, 170 &, 0013 &, 0008 & 1,58 &, 146 \\
\hline
\end{tabular}




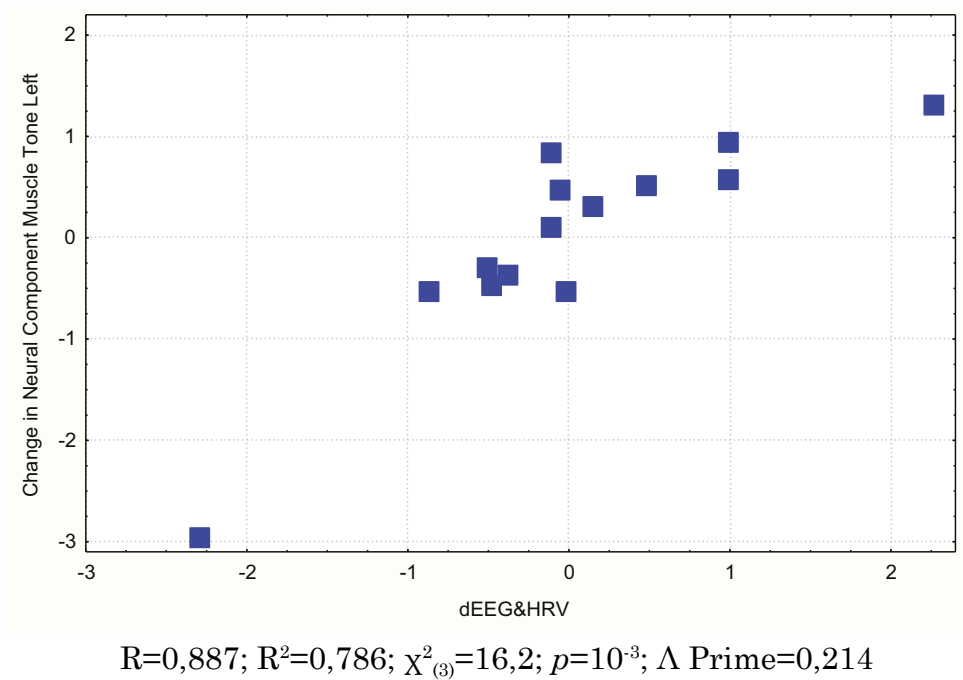

Fig. 3. Scatterplot of canonical correlation between changes in parameters of EEG\&HRV (line $\mathrm{X}$ ) and Neural Component of Muscle Tone of Left hand (line Y)

Now let's discuss the interactions between changes in manual tests and GDV parameters. But before doing it, let's discuss the argument and functions. If we adopt the paradigm of the Western medicine, then changes in the photoelectron emission of the skin should be interpreted as a result of neuroendocrine effects on metabolism. Instead, from the point of view of the paradigm of Oriental medicine, the photoelectric emission is characterized by the state of Chakras as energy centers that control nervous, endocrine and other systems [cyt. by: 12]. We will consider GDV parameters as arguments (causes) while manual tests as functions (effects).

According to the outcome of the canonical analysis, the maximum negative (here only the adverse effect is reflected) factor load on the root of the changes in GDV gives Entropy of GDI in the Right projection registered with the filter (Table 6).

Factor Structure for changes in parameters of GDV (right set) and Manual Function (left set)

\begin{tabular}{|l|c|}
\hline Right set & R \\
\hline Entropy R f &,- 768 \\
\hline Entropy F f &, 446 \\
\hline Shape Coef R &, 368 \\
\hline Entropy L f &, 260 \\
\hline Entropy R &, 107 \\
\hline Area F &,- 008 \\
\hline Left set & R \\
\hline D R &, 898 \\
\hline D L &, 866 \\
\hline 9-HP L &,- 657 \\
\hline 9-HP R &,- 494 \\
\hline B\&B R &, 523 \\
\hline B\&B L &, 352 \\
\hline
\end{tabular}


Entropy is registered in the same projection without any filter as well as in the Frontal and Left projections with the filter, gives positive (favorable) factor loads. In the regressive model with some step-by-step exclusion, six parameters have been included, the changes which together determine the changes in the manual functional tests as it can be seen by the $\mathrm{R}^{2}$ level, by $95 \%$ (Fig. 4)

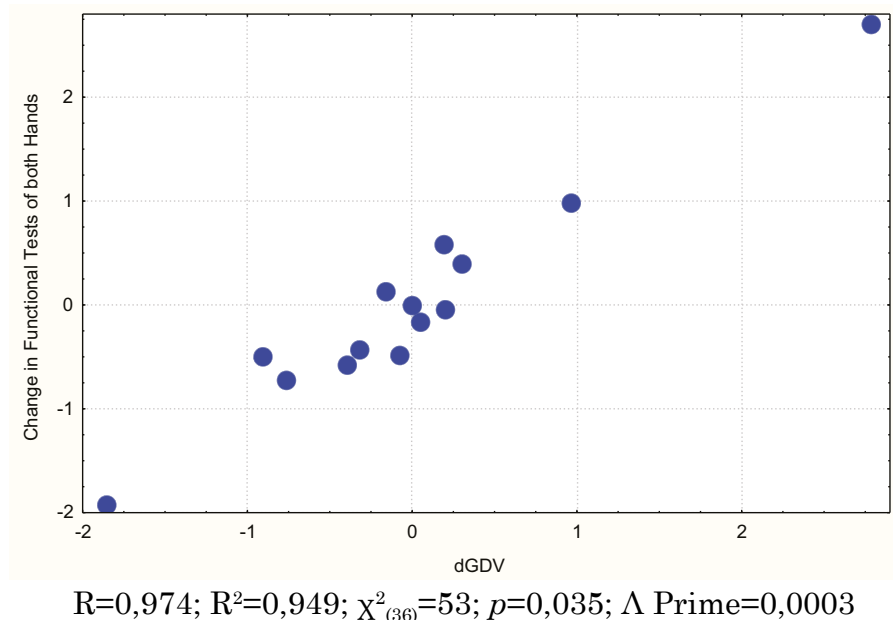

Fig. 4. Scatterplot of canonical correlation between changes in parameters of GDV (line X) nd Functional tests for both hands (line Y)

The same can also be applied to the role of changes in Entropy, in the Neural Component of Muscle Tone (Table 7 and Fig. 5).

Table 7

\section{Regression Summary for change in Dependent Variable: Neural Component of} Muscle Tone for Left hand

$\mathrm{R}=0,746 ; \mathrm{R}^{2}=0,556 ;$ Adjusted $\mathrm{R}^{2}=0,423 ; \mathrm{F}(3,1)=4,2 ; p=0,037$; $\mathrm{SE}$ of estimate: 5,9 Newtons

\begin{tabular}{|l|c|c|c|c|c|c|c|}
\hline $\begin{array}{c}\text { Change in } \\
\text { Independent } \\
\text { Variables }\end{array}$ & $\mathrm{r}$ & Beta & $\begin{array}{c}\text { St. Err. } \\
\text { of Beta }\end{array}$ & $\mathrm{B}$ & $\begin{array}{c}\text { St. Err. } \\
\text { of B }\end{array}$ & $\mathrm{t}_{(10)}$ & $\mathrm{p}$-level \\
\cline { 3 - 8 } & & Intercpt & $-5,93$ & 1,75 & $-3,39$ &, 007 \\
\hline Entropy R f & 0,58 &, 458 &, 223 & 34,2 & 16,6 & 2,05 &, 067 \\
\hline Symmetry f, \% & 0,41 &, 294 &, 223 &, 83 &, 63 & 1,32 &, 218 \\
\hline Entropy L f & $-0,42$ &,- 407 &, 212 & $-16,6$ & 8,6 & $-1,92$ &, 084 \\
\hline
\end{tabular}

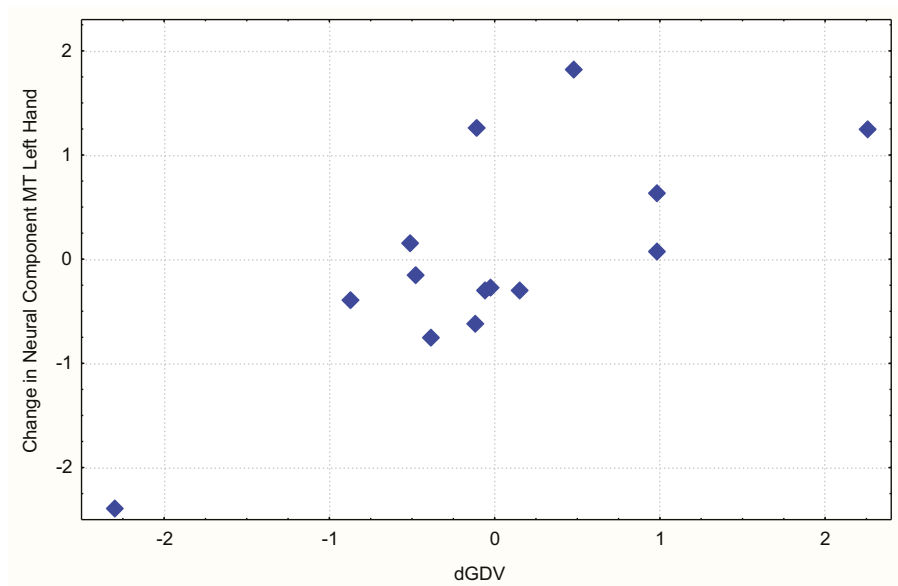

$\mathrm{R}=0,746 ; \mathrm{R}^{2}=0,556 ; \mathrm{X}_{(3)}^{2}=8,5 ; p=0,036 ; \Lambda$ Prime $=0,444$

Fig. 5. Scatterplot of canonical correlation between changes in parameters of GDV (line X) and Neural Component of Muscle Tone of Left hand (line Y) 
It is important to mention that the favourable changes in the NCMT are caused by the decrease in the symmetry of GDI. The obtained data confirm the normality of asymmetry and abnormality of symmetry. These data are not entirely consistent with K.G. Korotkov's statement [16] that GDI, taken without any filter, characterizes the current (functional) vegetative status and psychophysiological condition of a body, while registered with the filter characterizes the vegetative regulation at the level of stable (organic) physiological processes.

Conclusion. Despite the small number of the observed children with spastic cerebral palsy, it has been proved that differently directed changes in the parameters of manual tests caused by the two-week rehabilitation course by the Kozyavkin method are due to differently directed changes in parameters of EEG, HRV as well as GDV. The increase of the effectiveness of rehabilitation, perhaps, is possible through additional electrostimulation of the vagus nerve and/or certain scalp loci. GDV is a non-invasive method completely suitable for assessing the effectiveness of rehabilitation.

Acknowledgement. We express our sincere gratitude to the administration of JSC 'Truskavets' kurort' for helping in recording EEG and HRV.

Compliance with ethical standards. Tests of patients were conducted in accordance with the Declaration of Helsinki (1975), which was revised and complemented in 2002 and the directive of the Science Research Ethics Committee. During the tests the informed consent has been taken from all participants' parents and all necessary measures have been used for providing the anonymity of participants.

Authors state no conflict of interests.

\section{REFERENCES}

1. Amichai T, Katz-Leurer M. Heart rate variability in children with cerebral palsy: Review of the literature and mata-analysis. NeuroRehabilitation. 2014;35:113-22. 2. Babelyuk VY, Dubkova GI, Kikhtan VV, Korolyshyn TA, Zukow W, Popovych IL. The parameters of gas discharge visualization and principal neuroendocrine factors of adaptation closely correlated. // IX International symposium 'Actual problems of biophysical medicine' (Kyiv, 12-15 May 2016). Kyiv: Bohomolets' Institute of Physiology; 2016:9-10. 3. Babelyuk VY, Dubkova GI, Korolyshyn TA, Zukow W, Popovych IL. The correlationships between parameters of gas discharge visualization and principal neuroendocrine factors of adaptation. // Pathophysiology and Pharmacy: ways of integration. /Abstracts VII National Congress of Pathophysiologists Ukraine with international participation (5-7 October 2016). Kharkiv: NPhU;2016: 8. 4. Babelyuk VY, Gozhenko AI, Dubkova GI, Babelyuk NV, Zukow W., Kovbasnyuk MM, Popovych IL. Causal relationships between the parameters of gas discharge visualization and principal neuroendocrine factors of adaptation. Journal of Physical Education and Sport. 2017;17(2):624-37. 5. Babelyuk VY, Dubkowa GI, Korolyshyn TA, Holubinka SM, Dobrovol's'kyi YG, Zukow W, Popovych IL. Operator of Kyokushin Karate via Kates increases synaptic efficacy in the rat Hippocampus, decreases C3- $\theta$-rhythm SPD and HRV Vagal markers, increases virtual Chakras Energy in the healthy humans as well as luminosity of distilled water in vitro. Preliminary communication. Journal of Physical Education and Sport. 2017;17(1):383-93. 6. Bayevskiy RM, Ivanov GG. Heart Rate Variability: theoretical aspects and possibilities of clinical application [in Russian]. Ultrazvukovaya i funktsionalnaya diagnostika. 2001;3:106-27. 7. Berntson GG, Bigger JT, Eckberg DL, Grossman P, Kaufman PG, Malik M, Nagaraja HN, Porges SW, Saul JP, Stone $P H$, Maurits van der Molen. Heart Rate Variability: Origines, methods, and interpretive caveats. Psychophysiology. 1997;34:623-48. 8. Eliasson AC, Krumlinde SL, Rösblad B, Beckund E, Arner $M$, Öhrvall AM, Rosenbaum P. The Manual Ability Classification System (MACS) for children with cerebral palsy: scale development and evidence of validity and rehabilitee. Developmental Medicine Child Neurology. 2006;48:549-54. 9. Gäverth J, Sandgren M, Lindberg PG, Forssberg $H$, Eliasson ACh. Test-retest and inter-rater reliability of a method to measure wrist and finger spasticity. Journal of Rehabilation Medicine. 2013;45(7):630-36. 10. Gäverth J, Eliasson ACh, Kullander K, Jörgen B, Lindberg PG, Forssberg $H$. Sensitivity of the NeuroFlexor method to measure change in spasticity after treatment with botulinum toxin A in wrist and finger muscles. Journal of Rehabilation Medicine. 2014;46(7):629-34. 11. Gozhenko AI, Sydoruk NO, Babelyuk VY, Dubkova GI, Flyunt VR, Hubyts'kyi VY, Zukow W, Barylyak LG, Popovych IL. Modulating 
effects of bioactive water Naftussya from layers Truskavets' and Pomyarky on some metabolic and biophysic parameters at humans with dysfunction of neuro-endocrine-immune complex. Journal of Education, Health and Sport. 2016;6(12):826-42. 12. Heart Rate Variability. Standards of Measurement, Physiological Interpretation, and Clinical Use. Task Force of ESC and NASPE. Circulation. 1996;93(5):1043-65. 13. Kachmar O, Voloshyn T, Hordiyevych M. Changes in Muscle Spasticity in Patients With Cerebral Palsy After Spinal Manipulation: Case Series. Journal of Chiropractic Medicine. 2016;15:299-304. 14. Kerppers II, Arisawa EA, Oliveira LVF, Sampaio LMM, Oliveira CS. Heart rate variability in individuals with cerebral palsy. Archives of Medical Science. 2009;5(1):45-50. 15. Khaspekova NB. Diagnostic informativeness of monitoring HRV [in Russian]. Vestnik aritmologii. 2003;32:15-23. 16. Korotkov KG. Basics GDV Bioelectrography [in Russian]. SPb: SPbGITMO(TU); 2001. 360p. 17. Korotkov KG, Matrauers P, Orlov DV, Williams BO. Application of electrophoton capture (EPC) analysis based on gas discharge visualization (GDV) technique in medicine. A systematic review. Journal of Alternative and Complementary Medicine. 2010;16(1):13-25. 18. Kozyavkin V.I. The system of intensive neurophysiological rehabilitation [in Ukrainian]. Medical Hydrology and Rehabilitation. 2003;1(2):63-7. 19. Kozyavkin VI, Sak NM, Kachmar OO, Babadahly MO. Basics of Rehabilitation of Motor Disfunctions by the Kozyavkin method [in Ukrainian]. L'viv: Ukrainian technologies; 2007. 192p. 20. Kozyavkin VI, Babadahly MO, Lun HP, Kachmar OO, Hordiyevych SM, Lysovych VI, Voloshyn B.D. Intensive Neurophysiological Rehabilitation System - the Kozyavkin method. A manual for Rehabilitation Spetialists. L'viv: Papuga Publishing House; 2012. 240. 21. Kozyavkin V.I., Kozyavkina O.V., Kozyavkina N.V., Gordiyevych M.S., Lysovych V.I., Voloshyn TV, Zukow $W$, Popovych IL. Estimation of effectivenes of spine biomechanical correction Kozyavkin method (INRS) in children with spastic form of cerebral palsy. Journal of Education, Health and Sport. 2015;5(2):208-17. 22. Kozyavkin VI, Kozyavkina NV, Kozyavkina OV, Gordiyevych MS, Lysovych VI, Voloshyn TB, Popovych IL, Zukow W. Effect of spine biomechanical correction Kozyavkin's method (INRS) on components of muscle tone in children with spastic form of Cerebral Palsy and its possible prediction. Journal of Education, Health and Sport. 2015;5(1):11-30. 23. Kozyavkin VI, Kachmar OO, Voloshyn TB, Hordiyevych MS. Muscular tone components and methods of quantitative measurement of spasticity [in Ukrainian]. Journal of Neuroscience of BM Mankovskyi. 2015;3(1):72-6. 24. Kozyavkina OV, Kozyavkina NV, Gozhenko OA, Gozhenko AI, Barylyak LG, Popovych IL. Bioactive Water Naftussya and Neuroendocrine-Immune Complex [in Ukrainian]. Kyiv: UNESCO-SOCIO; 2015. 349. 25. Lafayette Instrument Hand Dynamometer. User instructions: 10 p. 26. Lindberg PG, Gäverth J, Islam M, Fagergren A, Borg J, Forssberg $H$. Validation of a new biomechanical model to measure muscle tone in spastic muscles. Neurorehabil Neural Repair. 2011;25(7):617-25. 27. Mathiowetz V, Federman S, Wiemer D. Box and Block Test of Manual Dexterity: Norms for 6-19 Year Olds. Canadian Journal of Occupational Therapy. 1985;52(5):241-45. 28. Newberg AB, Alavi A, Baime M, Pourdehnad M, Santanna J, d'Aquili $E$. The measurement of regional cerebral blood flow during the complex cognitive task of meditation: a preliminary SPECT study. Psychiatry Research: Neuroimaging Section. 2001;106:113-22. 29. Padko VO. The state of the autonomic nervous system in patients with cerebral palsy [in Ukrainian]. //Intensive Neurophysiological Rehabilitation System (the Kozyavkin method). Scientific developments. Under the general editorship of Koziavkin V.I. L'viv-Truskavets': Institute of Medical Rehabilitation Problems; 2001:56-61. 30. Poole JL, Burtner PA, Torres TA, McMullen CK, Markham A, Marcum ML, Anderson JB, Qualls C. Measuring Dexterity in Children using the Nine Hole Peg Test. Journal of Hand Therapy. 2005;18(3):348-51. 31. Popovych IL, Lukovych YS, Korolyshyn TA, Barylyak LG, Kovalska LB, Zukow $W$. Relationship between the parameters heart rate variability and background EEG activity in healthy men. Journal of Health Sciences. 2013;3(4):217-40. 32. Popovych IL, Kozyaukina OV, Kozyavkina NV, Korolyshyn TA, Lukovych YuS, Barylyak LG. Correlation between Indices of the Heart Rate Variability and Parameters of Ongoing EEG in Patients Suffering from Chronic Renal Pathology. Neurophysiology. 2014;46(2):139-48. 33. Russell DJ, Avery LM, Walter SD, Hanna SE, Bartlett DJ, Rosenbaum PL, Palisano RJ, Gorter JW. Development and validation of item sets to improve efficiency of administration of the 66-item Gross Motor Function Measure in children with cerebral palsy. Developmental Medicine and Child Neurology. 2010;52(2):48-54. 34. Sydoruk NO, Chebanenko OI, Popovych IL, Zukow W. Comparative Investigation of Physiological Activity of Water Naftussya from Truskavets' and Pomyarky Deposits [in Ukrainian]. Kyiv: UNESCO-SOCIO; 2017. 216p. 35. Wang YC, Magasi SR, Bohannon RW, Reuben DB, McCreath HE, Bubela DJ, Gershon RC, Rymer WZ. Assessing Dexterity Function: A Comparison of Two Alternatives for the NIH Toolbox. Journal of Hand Therapy. 2011;24(4):313-321. 


\title{
RESEARCH ARTICLES \\ Relationships between changes in parameters of the manual function and electroencephalogram, heart rate variability as well as gas discharge visualization in children with spastic cerebral palsy caused by the Kozyavkin method
}

\author{
I.L. POPOVYCH', V.Y. BABELYUK', H.I. DUBKOVA', T.A. KOROLYSHYN ${ }^{1,2}$, \\ W.ZUKOW \\ 1 Bogomoletz Institute of Physiology of NAS, Kÿ̈v, Ukraine \\ 2 Clinical Sanatorium 'Moldova', Truskavets', Ukraine \\ 3 Nicolaus Copernicus University, Torun', Poland \\ email:i.popovych@biph.kiev.ua,w.zukow@.wp.pl
}

Introduction. It was reported earlier that in children with spastic forms of cerebral palsy (SFCP) after two-week course of rehabilitation by the Kozyavkin method the neural component of muscle tone (NCMT) was reduced in $79,3 \%$ cases, while in $13,8 \%$ cases changes were not detected and in 2 children even increased. It was assumed that such a variety of changes in NCMT is due to differently directed changes in the background activity of the nerve centers.

Objectives. To analyse the relationships between changes (Ch) in NCMT as well as manual functional tests on the one hand, and parameters of EEG, HRV and Gas Discharge Visualization (GDV) on the other one.

Material and Methods. The object of observations were 14 children (6 girls and 8 boys) aged 8 $\div 15$ years with SFCP. The state of motor development at GMFCS was on II $\div$ IV level. The functional status of the hand with MACS was on II $\div$ III level. The estimation of hand function was carried out by Dynamometry (D), Box and Block Test (B\&B) and Nine Hole Peg Test (NHP). NCMT was also registered by the device 'NeuroFlexor' (Aggero MedTech AB, Sweden), HRV and EEG were tested simultaneosly by the hardware-software complex 'Cardiolab+VSR' and 'NeuroCom Standard' respectively (KhAI Medica, Kharkiv, Ukraine) as well as GDV by 'GDV Chamber' ('Biotechprogress', St-Pb, RF).

Results. After two-week course of rehabilitation NCMT was reduced in 9 children from $19,8 \pm 3,4$ to $12,3 \pm 2,8$ Newtons (Ch: $-7,5 \pm 2,0 \mathrm{~N}$ ), in 3 children NCMT was $8,2 \pm 3,3$ before and $7,9 \pm 3,5$ after rehabilitation (Ch: $-0,3 \pm 0,3 \mathrm{~N}$ ) while in one girl NCMT increased from 15,1 to $17,9 \mathrm{~N}$ and in one boy from 6,1 to 19,4 N. Manual functional tests also changed ambiguously. The $\mathrm{Ch}$ in NCMT are correlated with $\mathrm{Ch}$ in parameters HRV\&EEG $\left(\mathrm{R}^{2}=0,786\right)$ as well as GDV $\left(\mathrm{R}^{2}=0,556\right)$. The $\mathrm{Ch}$ in functional tests for the left hand are correlated with $\mathrm{Ch}$ in parameters HRV\&EEG to the stronger extent $\left(\mathrm{R}^{2}=0,931\right)$ and for the right hand the correlation is maximal $\left(\mathrm{R}^{2}=0,997\right)$. As to GDV parameters, connections are weaker but they are also stronger for the right hand.

Conclusion. In children with spastic forms of cerebral palsy caused by the Kozyavkin method, changes in manual functional tests and the neural component of the muscle tone are determined by changes in parameters of EEG and HRV as well as GDV which is a completely suitable non-invasive method for assessing the effectiveness of rehabilitation.

Key words: cerebral palsy, dynamometry, box and block test, nine hole peg test, neural component of muscle tone, EEG, HRV, GDV, intensive neurophysiological rehabilitation system by the Kozyavkin method. 